\title{
Impact of perceived social support and gender on creativity level of university undergraduates
}

\author{
Yousaf, Anam \\ University of Sargodha, Pakistan (anam.yousaf@ymail.com) \\ Ghayas, Saba $\measuredangle$ \\ University of Sargodha, Pakistan (saba.ghayas3@gmail.com)
}

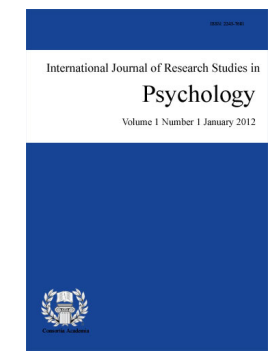

ISSN: $2243-7681$ Online ISSN: 2243-769X

OPEN ACCESS

\section{Abstract}

The present study examined the impact of perceived social support and gender on creativity level in a sample of university undergraduates. The present study was conducted on undergraduates taken from University of Sargodha through random sampling $(N=177$; M.A/M.Sc, II, and IV). Sample was comprised of boys $(n=74)$ and girls $(n=103)$. Urdu translated Interpersonal Support Evaluation List (Yousaf \& Ghayas, 2003) was used to measure perceived social support; while, creativity was assessed through Urdu translated Torrance Test of Creative Thinking (Shaheen, 2010). Analyses portrayed that perceived social support was significant and positive predictor of creativity. Gender difference was not found in perceived social support. Analysis revealed that girls were significantly high on creativity as compared to boys. The t-test analysis revealed that girl's scores were significantly high on fluency, abstractness of title, resistance to premature closure, abstractness of title, originality and fantasy than boys. While, boys scored high on internal visualization as compared to girls. Non-significant gender difference were found in elaboration, movement or action, storytelling articulateness, humor, expressiveness of title, colorfulness of imagery, unusual visualization, synthesis of lines, extending or breaking boundaries, synthesis of incomplete figure, richness of imagery. Limitation and suggestions for future studies have been discussed.

Keywords: perceived social support; gender; creativity; random sample; university undergraduate 


\section{Impact of perceived social support and gender on creativity level of university undergraduates}

\section{Introduction}

Perceived social support refers to the perception that the person is cared for, is valued, and is part of a group. Research indicates two prominent aspects of social support: perceived and received social support. Perceived social support is characterized with the perception that satisfactory assistance is provided by others, or to the perceived quality of one's support that can influence on level of adjustment. While, received social support is related with one's social network or the quantity of people present to help or give material or emotional aid (Asberg, Bowers, Renk, \& McKinney, 2008). Perceived social support has been found to have a consistently positive impact on well-being and other positive characteristics of individuals (Yap \& Devilly, 2004). As the research on the topic indicates that an individual's life satisfaction is directly related with perceived social support system (Duru, 2007). In line with this, social support is also linked with favorable and healthy outcomes (Malecki \& Demaray, 2003).

The results of comparative study on both constructs portrayed that perceived social support is directly linked with better and positive relationship with health outcomes than received social support. Since research has found that perceived social support predicts more comforting life with desirable health conditions along with higher well-being (Uchino, 2009). The work of Al-Srour and Al-Oweidi (2013) on university students with $(n=118)$ concluded that creativity goes inversely with psychological pressure as explaining the importance of social support in creativity. In this research creativity was assessed by Urdu translated Torrance Test of Creative Thinking (Shaheen, 2010) while Psychological Pressure Scale was used for measuring Psychological pressure.

Creativity is defined as the production of novel, appropriate ideas in any domain of human activity, as it practices frequently in every aspect and domain of life. Whether these are related to the concerns of educational field (science/arts); related to the field of business and management or to everyday life (Pryce, 2005). The influential work of Sternberg (2006) stated that creativity possess five major common features around the world. At first, creativity involves such type of thinking which mainly targets at producing ideas or products that are comparatively novel and in some respect, convincing. Secondly, creativity has some domain-specific and domain-general elements; as it needs some specific knowledge, but there are certain elements of creativity that cut across different domains. Thirdly, creativity is to some extent measurable. Fourth, it can be established as well as stimulated. And lastly, in practice creativity is not highly rewarded, as it is supposed to be in theory.

Cropley (2004) considered that something is determined as creative by the way people react to it, in that their willingness and ability to recognize creativity. He claimed that acceptance of a creative products depend upon its evaluation from the societal participants specially experts; as their positive opinion regarding a solution confirms the creativity. Therefore it has been suggested that the acceptance of creativity depend upon the decisions from surroundings. As, the important elements of a widely used explicit definition of creativity are linked with the element of originality and novelty in formation of ideas along with the acceptance of these ideas form majority of the individuals regarding the specific culture (Rudowicz, 2003).

There are 18 subcategories of creativity test; description of these subscales as given by Torrance and Safter (1999) is presented below:

$>$ Fluency. It is the ability to generate greater number of effective ideas or images.

$>\quad$ Originality. It refers to the production of unique and infrequent ideas on the stimuli.

$>$ Elaboration. It deals with the ability to add detailed and embellished description of ideas on figure. 
$>\quad$ Abstractness of titles. It refers to the labelling of the figure just beyond the concreteness. It measures the abstractness of labelling.

$>$ Resistance to premature closure. It is based on the belief that creative behaviour requires a person to consider a variety of information when processing information and to keep an open mind.

$>$ Emotional expressiveness. It is related to the communication of feelings and emotions through titles and drawings. These can be related to non-verbal and verbal cues (happy, sad).

$>\quad$ Storytelling articulateness. It refers to the presentation of image in a way that a complete story is conveyed.

$>$ Movement or action. It deals with the ability to add movement or action response in the figure (reading, jumping).

$>$ Expressiveness of titles. Visual information regarding feelings and emotions are communicated through title.

$>$ Synthesis of incomplete figures. Combination of 2 or more than two incomplete figures (only in activity 2).

$>\quad$ Synthesis of lines. Grouping two or more sets of lines (only in activity 3).

$>\quad$ Unusual visualization. This abilities refers to the presentation of an image in a different direction than it is actually perceived (above, below, different angle).

$>\quad$ Internal visualization. This ability is related to the emphasizing on insidious dynamics than only superficial images.

$>$ Extending or breaking boundaries. It is the ability to encompass the lines of original stimuli in order to make it more meaningful (up, down).

$>$ Humor. Presentation of the figure in such a way that the element of humor is prominent (caption, drawing).

$>$ Richness of imagery. Demonstrating variety of more vivid, fresh and lively images on stimuli.

$>$ Colorfulness of imagery. It refers to the ability to produce earthiness or excitingness in drawing.

$>$ Fantasy. Exhibiting those concepts in figure which are related to the fairy tales, science fictions or does not exist in reality (talking mouse).

Previous researchers have also found important results regarding the relationship between perceived social support and creativity. Mahon, Yarcheski, and Yarcheski (1999) studied an adult sample ( $\mathrm{n}=68)$ in order to explore the relationship between perceived social support, and creativity. In that study creativity was assessed through adjective checklist of creative thinking; perceived social support which was measured with Personal Resource Questionnaire (PRQ, 85). Correlation analysis revealed significant positive relation between perceived social support and creativity. Moreover, the influential work of Yeh, Wu, \& Cheng (2000) presented that the perceived social support received from family is the key element of creativity development in children. In line with these, research conducted on student sample concluded that social support leads toward creative performance of students (Feldman, 1999). Another study regarding relationship among environmental influence and creativity on working population was conducted. For measurement of environmental influences Work Environment Inventory was used. The results of this study presented that among all the variables social support is more crucial element for creativity (Amabile, 1996). 
On the debate of gender differences in social support there are different views among researchers. Cumsille and Epstein (1994) found that males are expected to live up to certain social expectations that have been set and that if they were to share their feelings, it would be deemed as a sign of weakness. Hence, males tend to perceive lower social support because they are more likely to feel that they have no one to express their feelings to. Moreover, Kendler, Myers and Prescott (2005) who studied on 1,057 opposite-sex dizygotic twin pairs stated that females tend to have larger social contacts as compared to males. They also emphasized that the females have higher social support because they seek emotional support in their relationship. Not only this, women provide more emotional support to both men and women, and they get more help in return (Klauer \& Winkeler, 2002).

On the other side, results of another study conducted on a sample of East German migrants in a two-year follow-up study ( $n=235$; age: 14-66years) yielded that the level of social support gets higher in males than females with age. In contrary, female's perception is lower on social support with the growing age (Knoll \& Schwarzer, 2002). Another research presented that there was no significant difference between males and females university postgraduate students $(n=100)$ on perceived social support. In this study perceived social support was measured through Perceived Social Support Scale (Mahanta \& Aggarwal, 2013).

In creativity, studies using the Torrance Tests of Creative Thinking, Ogletree (1971) sampled $(n=1165)$ English, Scottish, and German children, 8 to 11 years of age, and found that English and German girls scored higher than boys on both verbal and figural batteries. In addition, upper-middle social class groups significantly outscored the middle- and lower-social classes on most measures. Children in the upper grade levels also scored higher on all the creativity variables, i.e. verbal test. Furthermore, girls excelled significantly over boys on all creativity measures, both verbal and figural. Additionally, Ikram and Ghayas (2007) also examined the gender differences in creativity level of school children. Analysis of data regarding the work on students in the geographical context of Pakistan has shown that girls are more creative as compared to the. Whereas, Sang (1991) conducted a study on a sample of Malaysian University students to get the gender differences in creativity. The findings indicated that the boys were more creative than girls in both figural creativity and verbal creativity as well as in each of the seven creativity components.

McLauglin (2008) found that in preschool and elementary levels it is more frequent for girls to obtain better scores on creativity than boys. Among middle and high school students results are more controversial. In some studies girls score higher, and in others boys do, though there are a slight larger number of studies that favor girls. Moreover, Naderi, Abdullah, Tengku, Sharir, and Kumar (2009) explored the effect of gender, creativity, and age with academic achievement among 153 undergraduates of Malaysian universities. The age of participants who completed the creativity test ranged from 18 to 27 years old. The results displayed that the females' mean score (33.21) was greater than the males' mean score (31.90) for creativity. However, no large differences in the standard deviations were found between females and males (females $=4.55 \&$ males $=4.36$ ).

The same slight advantage favoring women is found in studies that compare adults (Kuhn \& Holling, 2009). Likewise, Baer (2008) concluded that in majority of studies female subjects usually score higher than males. Research findings from present study will help in identifying whether perceived social support and creativity are related as far as Pakistani student population is concerned. Once a relationship is highlighted regarding this particular Pakistani context, our research can lay grounds for designing psychological intervention strategies which can facilitate in raising perceived social support. Though this relationship has already been studied in other cultures but it is important to work on it in Pakistan because of a lot of academic and social differences from other cultures. As raising students' perception of social support can give better results regarding creativity that can be beneficial for laying grounds for a more productive future. 


\section{Method}

\subsection{Objectives}

$>\quad$ To investigate the relation between perceived social support and creativity.

$>\quad$ To find out the gender differences in creativity and perceived social support.

\subsection{Hypothesis}

$>$ Perceived social support will be significant and positive predictor of creativity.

$>\quad$ The level of perceived social support will be higher among girls than boys.

$>\quad$ The level of creativity will be higher among girls than boys.

\subsection{Study Design}

For the present study cross sectional survey research design was adopted. In cross sectional studies, variables of interest in a sample of subjects are studied once and the relationships between them are determined (Hopkins, 2008).

\subsection{Sample}

The sample consisted of 177 university undergraduates from the total pool of 2090 students. Boys $(n=74)$ and girls $(n=103)$ both were given representation in the sample. Their age range was about 19 to 35 years $(M=$ $22, S D=1.4)$. The regular students of undergraduate program were selected through random sampling from 3 major disciplines. Total number of students from faculty of Social Sciences $(n=97)$; faculty of Management sciences $(n=36)$; and faculty of Pure Sciences $(n=44)$ were included in the present research.

\subsection{Measures}

Interpersonal Support Evaluation List (ISEL; Cohen, Mermelstein, Kamarck, \& Hoberman, 1985). To measure perceived social support an Urdu translated ISEL consisting of 12 items was used (Yousaf \& Ghayas, 2013). The scale consisting of three subscales; appraisal support $(2,4,6,11)$, belongingness support $(1,5,7,9)$ and tangible support $(3,8,10,12)$. Six items $(1,2,7,8,11,12)$ were reverse scored. It was a 4 point rating scale with response categories ranging from definitely true (4) to definitely false (1) with high score indicating high level of perceived social support. Reported alpha coefficient of ISEL with undergraduate students was ranging from .77 to .86 while alpha coefficient (.67) was yielded for the present sample.

Torrance Test of Creative Thinking (TTCT; Torrance, 1966). Creativity was assessed using the Urdu translated version of TTCT (Shaheen, 2010). As, this is a culture free test (Torrance, Ball, \& Safter, 2008) and can be administered to all ages, and specifically suggested in education sector (Kim, 2006).Higher the score on the test will reflect high creativity while low score reflect low level of creativity. It can be administered on group as well as individual level. There are two versions of the test, TTCT-Verbal and TTCT-Figural. This study used the TTCT-Figural version because it involves minimum writing. This version has two Forms, A and B. In the study Form A was administered because this is used before an intervention while Form B is used for post intervention and since no intervention was made.

Form A consists of three activities:

Activity 1: Picture Construction 
Yousaf, A., \& Ghayas, S.

Activity 2: Picture Completion

Activity 3: Pairs of Lines

It is scored on 2 major domains:

$>\quad$ Norm referenced measures: fluency, originality, elaboration, abstraction of titles, and resistance to premature closure.

$>$ Criterion referenced measures: emotional expressiveness, storytelling articulations, movement or action, expressiveness of titles, synthesis of incomplete figures, synthesis of lines, unusual visualization, internal visualization, extending or breaking boundaries, humor, richness of imagery, colorfulness of imagery, and fantasy.

According to the TTCT manuals of 1966 and 1974, the test-retest reliability coefficients (1-week, 2-week, 10-week, 6-month, and 3-year intervals) ranged from .50 to .93. The test requires 30 minutes completion time, 10 minutes for each activity. Additional time is required for familiarization with the research subjects.

\subsection{Procedure}

For the purpose of data collection, permission letters on behalf of Department of Psychology was given to the heads of different departments. After taking list of registered students from department (social sciences, management sciences, and pure sciences) further all the lists (23 departments) were assigned numbers in ascending order. Total participants of undergraduates of morning program were 2090. A random table (McBurney \& White, 2004) was used to select the participants, every time a new row was randomly selected from the table and the selected numbers were dragged from the lists. After this, the selected students were directly approached and then they were brought in the University library for test administration for the purpose of minimizing the environmental threats which can influence on the study.

Same procedure for administration of the creativity test was followed as presented by the author. According to the requirements of test administration, the seating arrangement was same (armed chairs) throughout the test administration. They were seated and provided with stationery. The important thing to consider for the seating arrangements was to ensure that there was sufficient space for the test booklet and between each student to prevent copying. All the students were seated in u-shaped so the researcher could easily move from one student to another. Students were briefed about the consent form and necessary information regarding research. Before test administration the required personal information was obtained through the demographical sheet and the confidentiality of their information was ensured.

For each activity of TTCT the students were asked to turn to the required page. The researcher also showed the page, indicating to the stimulus and the accompanying instructions. The instructions were read out loud from the Urdu instructions manual and the students followed the written text from their own test booklets. The students then read the instructions either silently or aloud. Some students were asked to repeat the instructions. Effort was made to ensure that all the instruction has been understood. If not, they were repeated again in Urdu language. Students were encouraged to ask if they did not understand instructions or the meaning of any words. After completing the scales, they were thanked for their participation. Manual was consulted for scoring of TTCT

\section{Results}

Table 1 exhibits the inter-rater reliability of the 18 subscales of Torrance test of Creative Thinking (TTCT) between two scorers. It indicates the satisfactory level of reliability ranging from .71 to 1.00 . This shows the high level of objectivity and appropriateness in the scoring of TTCT. Results revealed that Torrance test of creative thinking is reliable for this particular sample. 
Impact of perceived social support and gender on creativity level of university undergraduates

Table 1

Inter-Rater Reliability among the Subscales of Torrance Test of Creative Thinking (TTCT) $(n=177)$

\begin{tabular}{|c|c|c|}
\hline Sr. No. & Subscales of TTCT & $r$ \\
\hline & Total TTCT & .91 \\
\hline 1 & Fluency & 1.00 \\
\hline 2 & Originality & 1.00 \\
\hline 3 & Elaboration & .99 \\
\hline 4 & Abstractness of Title & 1.00 \\
\hline 5 & Resistance to Premature Closure & .92 \\
\hline 6 & Emotional Expressiveness & 1.00 \\
\hline 7 & Storytelling Articulateness & .85 \\
\hline 8 & Movement or Action & .92 \\
\hline 9 & Expressiveness of title & .79 \\
\hline 10 & Synthesis of Incomplete Figures & 1.00 \\
\hline 11 & Synthesis of lines & 1.00 \\
\hline 12 & Unusual Visualization & .71 \\
\hline 13 & Internal Visualization & .75 \\
\hline 14 & Extending or Breaking Boundaries & 1.00 \\
\hline 15 & Humour & .77 \\
\hline 16 & Richness of Imagery & 1.00 \\
\hline 17 & Colourfulness of Imagery & 1.00 \\
\hline 18 & Fantasy & .83 \\
\hline
\end{tabular}

Table 2 postulates mean standard deviations and internal consistency index (alpha coefficients) of all the variables analyzed in present study.

Table 2

Mean, SD, Internal Consistency and Correlation Matrix for all the Variables Used in the Study $(n=177)$

\begin{tabular}{|c|c|c|c|c|c|c|c|c|}
\hline & Variables & $M$ & $S D$ & $\alpha$ & 2 & 3 & 4 & 5 \\
\hline 1 & Perceived social support & 36.96 & 5.85 & .67 & $.79 * *$ & $.73 * *$ & $.76 * *$ & $.22 * *$ \\
\hline 2 & Appraisal SS & 12.62 & 2.76 & .59 & -- & $.34 * *$ & $.40 * *$ & .11 \\
\hline 3 & Belonging SS & 11.81 & 2.47 & .22 & -- & -- & $.33 * *$ & $.24 * *$ \\
\hline 4 & Tangible SS & 12.53 & 2.49 & .46 & -- & -- & -- & $.15^{*}$ \\
\hline 5 & Creativity & & & & -- & -- & -- & -- \\
\hline
\end{tabular}

Table 3 explains that perceived social support is significant positive predictor of creativity $\{F(2,175)=8.73$, $\beta=.22, t=2.95, p<.01\}$ and it also demonstrates $5 \%$ variance in creativity that is contributed by perceived social support $\left(R^{2}=.05\right)$.

Table 3

Linear Regression Analysis of Perceived Social Support for Creativity ( $n=177)$

\begin{tabular}{lccccc}
\hline Predictor variable & $B$ & $B$ & $S . E$ & $R^{2}$ & $F$ \\
\hline Perceived social support (PSS) & .61 & .22 & .21 & .05 & $8.73^{* *}$ \\
\hline Note. ${ }^{* * p}<.01$ &
\end{tabular}

Analysis shows that there are non-significant mean differences in boys and girls on perceived social support. It further indicated that the mean scores of girls significantly surpasses on fluency $(M=33.85, S D=6.31)$ as compare to boys $(M=26.65, S D=7.57)$. In the same line, girls perform significantly high on premature closure $(M=4.12, S D=2.69)$ than boys $(M=2.86, S D=2.3)$. Significant high scores of girls are found on abstractness of title $(M=1.93, S D=3.49)$ to boys $(M=1.12, S D=1.61)$. Girls perform significantly better on originality $(M$ $=20.31, S D=5.79)$ in which boys scores are $(M=16.23, S D=6.36)$. 
Yousaf, A., \& Ghayas, S.

Analysis further reveals that, scores of girls are significantly high on emotional expressiveness $(M=1.05$, $S D=.69)$ than boys $(M=.74, S D=.62)$. It also displays significant mean differences of girls on fantasy $(M$ $=.46, S D=.57)$ as compare to boys $(M=.26, S D=.50)$. In contrary, the score of boys significantly surpasses on internal visualization $(M=.65, S D=.58)$ than girls $(M=.45, S D=.56)$.

Table 4

Mean, Standard Deviation and t-test Analysis for perceived social support and creativity $(n=177)$

\begin{tabular}{|c|c|c|c|c|c|c|c|c|c|}
\hline \multirow[b]{2}{*}{ Variables } & \multicolumn{2}{|c|}{$\begin{array}{c}\text { Boys } \\
(n=74)\end{array}$} & \multicolumn{2}{|c|}{$\begin{array}{c}\text { Girls } \\
(n=103)\end{array}$} & \multirow[b]{2}{*}{$t(175)$} & \multirow[b]{2}{*}{$p$} & \multicolumn{2}{|c|}{$95 \% C I$} & \multirow{2}{*}{$\begin{array}{c}\text { Cohen's } \\
d\end{array}$} \\
\hline & $M$ & $S D$ & $M$ & $S D$ & & & $L L$ & $U L$ & \\
\hline $\begin{array}{l}\text { Perceived Social } \\
\text { Support }\end{array}$ & 36.20 & 6.39 & 37.50 & 5.41 & -1.46 & .14 & -3.05 & .45 & .22 \\
\hline Creativity & 62.32 & 15.50 & 77.17 & 13.90 & -6.67 & .00 & -19.23 & -10.46 & 1.00 \\
\hline Fluency (N) & 26.65 & 7.57 & 33.85 & 6.31 & -6.89 & .00 & -9.27 & -5.14 & 1.04 \\
\hline Elaboration & 5.36 & 1.31 & 5.67 & 1.43 & -1.45 & .14 & -.72 & .11 & .23 \\
\hline Closure & 2.86 & 2.3 & 4.12 & 2.69 & -3.22 & .00 & -2.02 & -.48 & .50 \\
\hline Abstractness & 1.12 & 1.61 & 1.93 & 3.49 & -2.07 & .04 & -1.58 & -.04 & .31 \\
\hline Originality & 16.23 & 6.36 & 20.31 & 5.79 & -4.44 & .00 & -5.90 & -2.27 & .67 \\
\hline Emotions (C) & .74 & .62 & 1.05 & .69 & -3.02 & .00 & -.51 & -.11 & .47 \\
\hline Movement & 1.00 & .70 & 1.17 & .69 & -1.56 & .12 & -.37 & .04 & .24 \\
\hline Fantasy & .26 & .50 & .46 & .57 & -2.47 & .01 & -.36 & -.04 & .37 \\
\hline Story telling & .68 & .60 & .86 & .69 & -1.90 & .05 & -.38 & .01 & .28 \\
\hline Humor & .15 & .36 & .16 & .39 & -.12 & .90 & -.12 & .11 & .03 \\
\hline Internal & .65 & .58 & .45 & .56 & 2.34 & .02 & .03 & .37 & .35 \\
\hline Expressiveness & .18 & .42 & .31 & .61 & -1.75 & .08 & -.29 & .02 & .25 \\
\hline Colorfulness & 1.91 & .38 & 1.97 & .17 & -1.39 & .16 & -.16 & .03 & .21 \\
\hline Unusual & 1.14 & .75 & 1.18 & .68 & -.46 & .64 & -.26 & .16 & .06 \\
\hline Lines & .43 & .72 & .55 & .81 & -1.04 & .29 & -.35 & .11 & .16 \\
\hline Boundaries & 1.97 & .16 & 1.97 & .22 & .07 & .94 & -.06 & .06 & 0 \\
\hline Figure & .00 & .00 & .00 & .00 & .00 & .00 & .00 & .00 & .00 \\
\hline Richness & 1.00 & .70 & 1.17 & .69 & -1.56 & .12 & -.37 & .04 & .25 \\
\hline
\end{tabular}

\section{Discussion}

The present study aimed at finding out the impact of perceived social support and gender on creativity. In order to measure the psychometric properties of scales used in the study reliability analysis was carried out. Inter-rater reliability analysis on the subscales of TTCT has demonstrated highly satisfied values while alpha coefficient of Urdu language translated version interpersonal support evaluation list has also postulated good reliability level which was .67 (see Table 1 and 2).

First hypothesis of the study was supported by the analysis, as it has been depicted that perceived social support is significant positive predictor of creativity (see Table 3). These results are found to be in line with a study which revealed that perceived social support is significant and positive correlate of creativity among young adults (Mahon, Yarcheski, \& Yarcheski, 1999). Among the influential factors Ekvall and Tangeberg-Andersson (1986) found ten elements of society which impact on creativity. Among these ten factors, one of the influential factors is social support. They confirmed that lack of social support is the barrier of creativity. It has been clarified that for creativity social support is crucial element. It is considered that creativity is, in part, a social process. In two prominent creativity models (Amabile, 1988; Woodman, Sawyer, \& Griffin, 1993), researchers proposed that the factors in the every type of work environment, such as supervisory support and social influences resulting from group interaction are important antecedents to creativity.

They further postulated that communication of ideas and information among people does very well with creativity. Likewise, former research anticipated the idea that weaker relationships do negatively influence on creativity (Brass, 1998). Thus it can be claimed that strong social ties are beneficial for creativity. Similarly, 
Impact of perceived social support and gender on creativity level of university undergraduates

almost each and every work environment emphasize on strong bonding of relationships for the betterment of quality and excellence of work. Specifically in education settings for increasing the production of unique ideas among students, extensive work is assigned in groups rather than on individual basis.

In the existing study it was hypothesized that the level of perceived social support would be higher among girls as compared to the boys. Analysis has revealed non-significant gender differences (see Table 4). The work of Pfeifer and Asberg (2011) supported the current results. They conducted work on undergraduates Psychology students of a public university of South-eastern region and results revealed no gender differences in perception about availability of social support.

The reason for no gender differences on perceived social support might be the changing trends in the grooming of children. In present circumstances, maximum and equal efforts regarding the opportunities and trainings are provided to the children (boys and girls) at their initial stage of development to their maximum level. These equal opportunities are obvious in the preference of their schooling, costumes, religious beliefs and also the weightage which is given to their views for each and every matter. This healthy practice may cause no gender differences. Moreover, the sample was collected form the same geographical context with almost same practices and trainings which ultimately leads toward less chance of diverse variety. Furthermore, the results for non-significant gender differences can also be influenced by the nature of the scale used in the study. It is an admitted fact that explicit measures are contaminated by the fact of social desirability and are more prone toward presentation biases (Holtgraves, 2004). Similarly, Nosek (2005) suggested that these biases can be intrapersonal which is related to self-deception, or intrapersonal (evaluation apprehension or intention to impress).

The third hypothesis of the study was that girls will significantly score higher on creativity than boys. Analysis of the data has revealed that girls' level of creativity was significantly higher as compared to boys (see Table 4). Creativity is taken as originality and usefulness specially regarding problem solving. A strong body of researches are also in line with the results of current study (Kuhn \& Holling, 2009; Wolfradt \& Pretz, 2001). Similarly research conducted on verbal and performance test of creative thinking on adult sample has postulated that there are gender difference in verbal and performance test of creative thinking (Matud, Rodriguez, \& Grande, 2007). Results of the current study are also supported by previous Pakistani researches. Ikram and Ghayas (2007) found that girls significantly outperformed on Wallach-Kogan creativity test as compared to boys. The results of another study conducted in geographical context of Pakistan revealed significant gender differences in performance creativity test (Wallach-Kogan) elaborating the outperformance of girls than boys (Shakeel, Ghayas, \& Adil, 2011).

It is accepted that the ability of processing information differs in both genders; therefore these differences in ability may strongly impact on their performance on creativity test. Secondly it can be anticipated that with the growing changes in the cultural trends, girls are equally preferred in each and every field of life whether it is related to their education, career, and decision making. These influential changes may be the contributor in the progress of girls in creativity. As well as, girls' outperformance on creativity can also depend upon the field of study. As, it is frequently considered that girls creative achievements are better in the domain of musical performance, dance, drama, and writing, as compare with the creative achievements of boys. The creative achievement of males significantly surpasses females in the area of science, musical composition, and painting (Vernon, 1989); and creative technical development (Eysenck, 1995). Therefore it indicated the notion that girls and boys both are creative but their creativity varies in different domains. Baer (2008) has concluded the fact that the differences of gender are not consistent in many researches but it can be claimed that usually female subjects score higher than males. In order to get the clear picture of gender differences in different subscales of creativity further analysis was carried out. Results revealed that mean score of girls on fluency, premature closure, abstractness of title, originality and emotional expressiveness are significantly higher than boys. Moreover findings revealed that the scores of boys are significantly higher on internal visualization than girls. 
These findings are in consistent with the previous research concluding that the creative performance of girls yield higher scores on fluency, flexibility and originality as compared with boys (Hong, Peng, O'Neil, \& Wu, 2013). In the same line, work of Sax (2005) yielding that girls mostly focus on the emotional side of a task that is why they gave responses which are related to feelings, emotions, and desires. It was further elaborated that girls outperform on fluency, flexibility and originality as compared to boys. On the other hand responses of boys are mainly concerned with actions and imagination. A strong reason of boys higher scores on internal visualization can be their nature of in-depth analysis of everything rather than mere superficial picture. In religious perspective it may also be justified that as being more focused on in depth investigative abilities the right of major decisions (divorce, household management) is given to boys because girls are more emotional and on the basis superficial representation makes decisions. A growing research supported that males are more inclined to have an active and involved attitude in the perception and understandings of the world; specifically regarding the management through reasonable and competitive skills and resources; whereas, females tend to have more emotional attitude.

There is also a fairly important body of researches indicating that women are actually the more emotionally expressive gender (Brody \& Hall 2000; Johnson \& Shulman 1988). Similarly, results of another important study yielded that the emotions of happiness, sadness and fear are extensively expresses by girls (Parkins, 2012).

\section{Conclusion}

It can be concluded that perceived social support significantly and positively predicted creativity. Furthermore, gender was found to have significant effect on creativity while non-significant gender differences were found in perceived social support. Among the subscales of TTCT, girls significantly score high on fluency, originality, resistance to premature closure, abstractness of title and emotional expressiveness than boys. While boys significantly score high on internal visualization as compare to girls.

\subsection{Limitations of Study}

The present cross-sectional study has exposed very important findings; however it has also carried many concerns which should be considered in future.

$>\quad$ In present study no consideration was taken regarding the developmental stages in patterns of creative thinking.

$>\quad$ Moreover, relying only on one method of data collection can deteriorate the findings.

$>\quad$ As well as, in current study no consideration was taken for checking the comparative influence of education sector (private/public) which may also plays vital role on the interested variables.

$>$ Furthermore, the performance test of creative thinking was basically a speed test; the performance of participants on creativity test might be influenced by specific time period required for completion of each activity.

\subsection{Further Recommendations}

The following suggestions are given on the basis of aforementioned limitations:

$>\quad$ It was found that several extensive studies are required regarding creative thinking development specifically regarding the critical period of growth and decline in creative abilities. It is significant to place special emphasis on creative thinking development and the declines or inclines which frequently occur in the specific period.

$>\quad$ Education system put the most powerful effect for determining the creative abilities of a person. As it plays vital role in the process of development or decline in creative patterns of students. So it is crucial 
Impact of perceived social support and gender on creativity level of university undergraduates

to put forward steps for the betterment of education system which may flourish the practice of creativity among students. For this purpose special training programmes regarding creative development should be organized for teachers which will surely help them in understanding the needs and basis of creativity not only for education system but also for the betterment of the whole society. The practice of this training shall be practised in class rooms which will definitely increase the probability of novelty, imaginative power and tolerance abilities for ambiguity among students. This practice should be started with the very early and young students. The growth in creativity talent not only fosters their cognitive abilities but also go along with groomed and confident personality.

$>\quad$ For more comprehensive picture of findings, personality characteristics should be controlled or treated as variable for further research.

\subsection{Implications of the Study}

$>\quad$ Findings of present research would be helpful for social psychologists, educational psychologists and family counsellors in many perspectives. Specifically it will be beneficial for administration of education system to plan such strategies which will be helpful for creativity enhancements. Specially, educational psychologists will gain more insight to deal easily and appropriately with those students who just because of problematic social relations have problems in expression of creativity. Not only in education scenario but also in organizational set-up, creativity is the only thing which contributes toward more turnovers.

$>$ Along with it, the performance test which is used for measurement of creativity among adults is also first step toward its practice in Pakistan; it will definitely enhance the insight toward the administration of this test in future research plans. Specifically regarding to TTCT, very strong results of inter-rater reliability in geographical context of Pakistan will increase the confidence on its objective scoring.

Acknowledgement - I would in particular sincerely thank to my family members whom sincere prayers and support I always felt around me. It is because of them that I took on the challenge of higher education.

\section{References}

Al-Srour, H. N., \& Al-Oweidi, A. (2013). The relationship between psychological pressure and creativity among graduate students in the University of Jordan. International Journal of Humanities and Social Science, 3(19), 133-136.

Amabile, T. M. (1988). A model of creativity and innovation in organizations. Research in Organizational Behaviour, 10, 123-167.

Amabile, T. M. (1996). Creativity in context: Update to the social psychology of creativity. Boulder, Colorado: Westview.

Asberg, K. K., Bowers, C., Renk, K., \& McKinney, C. (2008). A structural equation modeling approach to the study of stress and psychological adjustment in emerging adults. Child Psychiatry and Human Development, 39(4), 481-501. http://dx.doi.org/10.1007/s10578-008-0102-0

Baer, J. (2008). Evidence of gender differences in creativity. Journal of Creative Behaviour, 42(2), 78-105. http://dx.doi.org/10.1002/j.2162-6057.2008.tb01289.x

Brass, D. J. (1998). Technology, power, and diversity: A social network perspective. In G. Barnett (Ed.), Organization communication: Emerging perspectives (pp. 25-46). Stamford, CT: Ablex Publishing.

Brody, L. R., \& Hall, J. A. (2000). Gender, emotion, and expression. In M. Lewis, \& J. M. Haviland Jones (Eds.), Handbook of emotions (2nd ed., pp. 338-349). New York: Guilford. 
Yousaf, A., \& Ghayas, S.

Cohen, S., Mermelstein, R., Kamarck, T., \& Hoberman, H. M. (1985). Measuring the functional components of social support. In I .G. Sarason, \& B. R. Sarason (Eds.), Social support: Theory, research, and applications. The Hague, Netherlands: Martinus Niijhoff. http://dx.doi.org/10.1007/978-94-009-5115-0_5

Cropley, A. (2004). Creativity as a social phenomenon. In M. Fryer (Ed.), Creativity and cultural diversity (pp.13-23). Leeds, England: The Creativity Centre Educational Trust Press.

Cumsille, P. E., \& Epstein, N. (1994). Family cohesion, family adaptability, social support, and adolescent depression symptoms in outpatient clinic families. Journal of Family Psychology, 8(2), 202-214. http://dx.doi.org/10.1037/0893-3200.8.2.202

Duru, E. (2007). Re-examination of the psychometric characteristics of the Multidimensional Scale of Perceived Social Support among Turkish university students. Social Behavior and Personality: An International Journal, 35, 443-452. http://dx.doi.org/10.2224/sbp.2007.35.4.443

Ekvall, G., \& Tangeberg-Andersson, Y. (1986). Working climate and creativity: A study of an innovative newspaper office. Journal of Creative behaviour, 20(3), 215-225. http://dx.doi.org/10.1002/j.2162-6057.1986.tb00438.x

Eysenck, H. J. (1995). Genius: The natural history of creativity. Cambridge, MA: Cambridge University Press. http://dx.doi.org/10.1017/CBO9780511752247

Feldman, D. H. (1999). The development of creativity. In R. J. Sternberg (Ed.), Handbook of creativity (pp.169-186). New York: Cambridge University Press.

Holtgraves, T. (2004). Social desirability and self-reports: Testing models of socially desirable responding. Personality and Social Psychology Bulletin, 30, 161-172. http://dx.doi.org/10.1177/0146167203259930

Hong, E., Peng, Y., O'Neil Jr, F. H., \& Wu, J. (2013). Domain general and domain specific creative thinking tests: Effects of gender and item content on test performance. The Journal of Creative Behavior, 47(2), 89-105. http://dx.doi.org/10.1002/jocb.26

Ikram, F., \& Ghayas, S. (2007). Effect of birth order on creativity level of students. Unpublished Masteral thesis, Department of Psychology, University of Sargodha.

Johnson, J. T., \& Shulman, G. A. (1988). More alike than meets the eye: Perceived gender differences in subjective experience and its display. Sex Roles, 19, 67-79. http://dx.doi.org/10.1007/BF00292465

Kendler, K. S., Myers, J., \& Prescott, C. A. (2005). Sex differences in the relationship between social support and risk for major depression: A longitudinal study of opposite sex twin pairs. Am I Psychiatrist, 162, 250-256. http://dx.doi.org/10.1176/appi.ajp.162.2.250

Klauer, T., \& Winkeler, M. (2002). Gender, mental health status, and social support during a stressful event. In G. Weidner, M. Kopp, \& M. Kristenson (Eds.), Heart disease: Environment, stress, and gender. NATO Science Series, Series I: Life and Behavioural Sciences (vol. 327, pp. 223-236). Amsterdam: IOS Press.

Knoll, N., \& Schwarzer, R. (2002). Gender and age differences in social support: A study on East German refugees. In G. Weidner, M. Kopp, \& M. Kristenson (Eds.), Heart disease: Environment, stress, and gender. NATO Science Series, Series I: Life and Behavioural Sciences (vol. 327, pp. 198-210). Amsterdam: IOS Press.

Kuhn, J., \& Holling, H. (2009). Measurement invariance of divergent thinking across gender, age, and school forms. European Journal of Psychological Assessment, 25(1), 1-7. http://dx.doi.org/10.1027/1015-5759.25.1.1

Mahanta, D., \& Aggarwal, M. (2013). Effect of perceived social support on life satisfaction of university students. European Academic Research, 1(6), 1083-1084.

Mahon, E. M., Yarcheski, A., \& Yarcheski, J. T. (1999). Selected correlates of creativity in young adults. Psychological Reports, 84, 1246-1250. http://dx.doi.org/10.2466/pr0.1999.84.3c.1246

Malecki, C. K., \& Demaray, M. K. (2003). What type of support do they need? Investigating student adjustment as related to emotional, appraisal, information, and instrumental support. School Psychology Quarterly, 18(3), 231-252. http://dx.doi.org/10.1521/scpq.18.3.231.22576

Matud, M. P., Rodriguez, C., \& Grande, J. (2007). Gender differences in creative thinking. Personality and Individual Differences, 43(5), 1137-1147. http://dx.doi.org/10.1016/j.paid.2007.03.006 
Impact of perceived social support and gender on creativity level of university undergraduates

McBurney, H. D., \& White, L. T. (2004). Research methods. USA: Vicki knight.

McLaughlin, C. (2008). Emotional well-being and its relationship to schools and classrooms: A critical reflection. British Journal of Guidance and Counseling, 34(4), 353-366. http://dx.doi.org/10.1080/03069880802364486

Naderi, H., Abdullah, R., Tengku, A. H., Sharir, J., \& Kumar, V. (2009). Creativity, age and gender as predictors of academic achievement among undergraduate students. Journal of American Science, 5(5), 101-112.

Nosek, B. A. (2005). Moderators of the relationship between implicit and explicit evaluation. Journal of Experimental Psychology, 134, 565-584. http://dx.doi.org/10.1037/0096-3445.134.4.565

Ogletree, E. (1971). A cross-cultural examination of the creative thinking ability of public and private schools. Journal of Social Psychology, 83, 301-302. http://dx.doi.org/10.1080/00224545.1971.9922475

Parkins, R. (2012). Gender and emotional expressiveness: An analysis of prosodic features in emotional expression. Griffith Working Papers in Pragmatics and Intercultural Communication, 5(1), 46-54.

Pfeifer, J. C., \& Asberg, K. (2011). The effects of perceived social support and coping self-efficacy on trauma symptoms after a traumatic event. Published Masteral thesis. Department of Psychology, Graduate School of Western Carolina University.

Pryce, V. (2005). Creativity, design and business performance. Retrieved from http://www.publicaffairs.ubc.ca/media/releases/2009/mr-09-054.html

Rudowicz, E. (2003). Creativity and culture: A two way interaction. Scandinavian Journal of Educational Research, 47(3), 273-290. http://dx.doi.org/10.1080/00313830308602

Sang, L. U. M. (1991). Creativity and sex differences in Malaysian pupils. Asia Pacific Journal of Education, $11(2), 62-67$.

Sax, L. (2005). Why gender matters: What parents and teachers need to about the emerging science of gender differences. New York: Broadway Books.

Shaheen, R. (2010). An investigation into the factors enhancing or inhibiting primary school children creativity in Pakistan. Unpublished Doctoral dissertation, Department of Education, University of Bermingham.

Shakeel, S., Ghayas, S., \& Adil, A. (2011). Effect of handedness and gender on creativity of students. Biannual journal of Gender and social Issues, 10(1), 39-48.

Sternberg, J. R. (2006). The nature of creativity. Creativity Research Journal, 18(1), 87-98. http://dx.doi.org/10.1207/s15326934crj1801_10

Torrance, E. P. (1966). The Torrance Tests of Creative Thinking: Norms technical manual research edition verbal tests, forms A and B figural Tests. Princeton, NJ: Personnel Press.

Torrance, E. P. (1974). Norms technical manual: Torrance Tests of Creative Thinking. Lexington, Mass: Ginn and Co.

Torrance, E. P. (1990). The Torrance tests of creative thinking norms-technical manual figural (streamlined) forms $A$ \& B. Bensenville, IL: Scholastic Testing Service, Inc.

Torrance, E., \& Safter, H. (1999). Making the creative leap beyond. Buffalo: Creative Education Foundation Press.

Uchino, B. N. (2009). Understanding the links between social support and physical health: A lifespan perspective with emphasis on the separability of perceived and received support. Perspectives in Psychological Science, 4, 236-255. http://dx.doi.org/10.1111/j.1745-6924.2009.01122.x

Vernon, P. A. (1989). The nature-nurture problem in creativity. Handbook of creativity: Perspectives on individual differences. New York: Plenum Press.

Wolfradt, U., \& Pretz, J. E. (2001). Individual differences in creativity: Personality, story writing, and hobbies. European Journal of Personality, 15(4), 297-310. http://dx.doi.org/10.1002/per.409

Woodman, R. W., Sawyer, J. E., \& Griffin, R. W. (1993). Toward a theory of organizational creativity. Academy of Management Review, 18, 293-321.

Yap, M. B., \& Devilly, G. J. (2004). The role of perceived social support in crime victimization. Clinical Psychology Review, 24(1), 1-14. http://dx.doi.org/10.1016/j.cpr.2003.09.007

Yeh, Y. C., Wu, J.J., \& Cheng, Y.Y. (2000). The development of inventories for factors that influence creativity development for personnel in technology and information industries. Journal of National Taiwan 
Yousaf, A., \& Ghayas, S.

Normal University: Science Education, 45(2), 39-63.

Yousaf, A., \& Ghayas, S. (2003). Experience and perception of daydreaming: Daydreaming in relation with loneliness, perceived social support, and creativity. Unpublished Masteral thesis, Department of Psychology, University of Sargodha. 